Research Article

\title{
Pharmacovigilance study of angiotensin-converting enzyme inhibitors in patients visiting Department of Medicine of a Tertiary Care Hospital, Surendranagar, Gujarat
}

\author{
Madhav D. Trivedi ${ }^{1 *}$, Fenilkumar S. Kotadiya ${ }^{2}$, Manish K. Bavaliya ${ }^{3}$, Bhautik V. Tilva ${ }^{3}$, \\ Dimple S. Mehta ${ }^{1}$
}

\begin{abstract}
${ }^{1}$ Department of Pharmacology, C.U. Shah Medical College, Surendranagar, Gujarat, India, ${ }^{2}$ Department of Anatomy, M.P. Shah Medical College, Jamnagar, Gujarat, India, ${ }^{3}$ Department of Medicine, C.U. Shah Medical College \& Hospital, Surendranagar, Gujarat, India
\end{abstract}

Received: 08 August 2014 Accepted: 23 August 2014

*Correspondence to: Dr. Madhav D. Trivedi, Email: dr_madhav_trivedi@ yahoo.co.in

Copyright: (C) the author(s), publisher and licensee Medip Academy. This is an openaccess article distributed under the terms of the Creative Commons Attribution NonCommercial License, which permits unrestricted noncommercial use, distribution, and reproduction in any medium, provided the original work is properly cited.

\begin{abstract}
Background: The objective of this study was to evaluate incidence, patterns, and severity of angiotensin-converting enzyme inhibitor (ACEI) induced adverse drug reactions (ADR).

Methods: A total of 500 hypertensive patients taking ACEI was enrolled in the study by taking an informed consent. Reporting of all ACEI-induced ADRs was done by filling CDSCO ADR form. All ADR reports were evaluated according to WHO-UMC causality assessment scale.

Results: A total of 53 ADRs (31 males and 22 females) was observed in 500 hypertensive patients taking ACEI. Of 53 ADRs, 22 (41.51\%) were mild, 28 (52.83\%) were moderate, and only 3 (5.66\%) were classified as severe. 7 ADRs (13.21\%) were classified as certain, 30 ADRs $(56.60 \%)$ were in probable category, $8(15.09 \%)$ were in possible category, $4(7.55 \%)$ in unlikely category, $3(5.66 \%)$ in conditional category (unclassified), and 1 ADR was in unassessable (unclassifiable) category. Among 53 ADRs, $24(4.80 \%)$ patients developed dry cough, 8 (1.60\%) hypotension, $2(0.40 \%)$ headache, $2(0.40 \%)$ dizziness, $3(0.60 \%)$ nausea/bowel upset, $3(0.60 \%)$ rashes, $2(0.40 \%)$ developed angioedema, $3(0.60 \%)$ dysgeusia, hyperkalemia, acute renal failure, proteinuria are rare.

Conclusions: Incidence of ADRs by ACEIs is $10.60 \%$ with cough as the most common ADR followed by hypotension. As enalapril is most frequently used ACEI, ADRs due to enalapril are more common.
\end{abstract}

Keywords: Pharmacovigilance, Angiotensin-converting enzyme inhibitors, WHO-UMC scale

\section{INTRODUCTION}

According to WHO, pharmacovigilance is, "the science relating of detection, assessment, understanding and prevention of adverse effects or any other possible drug related problems."

According to $\mathrm{WHO}$, adverse drug reaction (ADR) is, "A response to a drug that is noxious and unintended and occurs at doses normally used in human for the prophylaxis, diagnosis and treatment of disease, or for modification of physiological function."2
Pharmacovigilance studies in India are in its infancy. But ADRs are considered among the leading causes of mortality and morbidity. Around $6 \%$ of hospital admissions are estimated to be due to ADRs, and about 6-15\% of hospitalized patients experience a serious ADR. ${ }^{3}$

When the Food and Drug Administration approves a new drug for marketing, its complete adverse advents profile may not be known due to the limitations of pre-approval clinical trials. Typically, clinical trials for new drugs are of short duration and are conducted in population that number up 
to 5000, therefore, long-term ADRs and even dose related long-term use are not known.

Angiotensin-converting enzyme inhibitors (ACEI) have added a new dimension to the treatment of hypertension, congestive heart failure, and post myocardial infarction, and are now playing an important role in the treatment of endothelial dysfunction. ${ }^{4}$ In hypertensive diabetic patients, and particularly those with albuminuria, treatment with ACEI may forestall the deterioration of renal function and diminish albuminuria. ${ }^{5}$ Unloading therapy in congestive heart failure with the use of ACEI along with the use of diuretics and digoxin has added another important adjunct in the care of a difficult situation, especially in patients with hypertension as well as diabetes mellitus.

While the benefits of ACEI treatment are important in cardiovascular diseases, coughing and other ADRs are common to all ACEI, sometimes requiring termination of treatment.

\section{Objectives}

The aim of our present study was to evaluate incidence, patterns, and severity of ACEI induced ADR in patients coming to the Department of Medicine at C.U. Shah Medical College, Surendranagar, Gujarat.

\section{METHODS}

The study protocol was approved by Institutional Ethics Committee (human). The present study was an open, noncomparative observational study to monitor ADRs associated with ACEI. The study was conducted between November 2010 and February 2011 at Department of Medicine on a daily basis. The total of 500 hypertensive patients, irrespective of age and sex, coming to Department of Medicine, and taking ACEI were enrolled in the study by taking an informed consent from each of them. All mentally compromised or unconscious patients and patients unable to respond to verbal questions were excluded from the study.

Reporting of all ACEI induced ADRs was done by filling CDSCO ADR Form. ${ }^{6}$ All ADR reports were evaluated according to "WHO-UMC causality assessment scale."7

\section{RESULTS}

A total of 53 ADRs (31 males and 22 females) was observed in 500 hypertensive patients taking ACEI during the 4 months of study with a mean age of $56.41 \pm 9.56$.

A higher \% of ADRs occurred in males 31 (58.49\%) than females $22(41.51 \%)$ are shown in Table 1.

As shown in Table 2, total of 8 ADRs (15.09\%) were observed in the patients group of 31-40 years, followed by 12 ADRs (22.64\%) were observed in 41-50 age group, $13(24.54 \%)$ in $51-60$ years, 9 (16.98\%) in 61-70 years, and 11 ADRs $(20.75 \%)$ were observed in above 70 years age group.

Table 3 displays out of 53 ADRs, 39 (73.58\%) were Type A reactions and 14 (26.42\%) were Type B reactions.

As shown in Table 4, of 53 ADRs, 22 (41.51\%) were mild, $28(52.83 \%)$ were moderate, and only $3(5.66 \%)$ were classified as severe (two patients developed angioedema and one patients developed acute renal failure $[\mathrm{ARF}]$ ).

Table 5 reveals that on the causality scale of WHO-UMC, 7 ADRs (13.21\%) were classified as certain, 30 ADRs (56.60\%) were in the probable category, $8(15.09 \%)$ were in possible category, $4(7.55 \%)$ in the unlikely category, $3(5.66 \%)$ in conditional category (unclassified), and only 1 ADR was observed in un-assessable (un-classifiable) category.

Table 1: Gender-wise distribution of patients with ADRs.

\begin{tabular}{|lcc|}
\hline Sex & Number of people & Percentage \\
\hline Male & 31 & 58.49 \\
\hline Female & 22 & 41.51 \\
\hline Total & 53 & 100 \\
\hline
\end{tabular}

ADR: Adverse drug reaction

Table 2: Age-wise distribution of patients with ADRs.

\begin{tabular}{|lc|}
\hline Age & Percentage \\
\hline $31-40$ & 15.09 \\
\hline $41-50$ & 22.64 \\
\hline $51-60$ & 24.54 \\
\hline $61-70$ & 16.98 \\
\hline$>70$ & 20.75 \\
\hline
\end{tabular}

ADRs: Adverse drug reactions

Table 3: Distribution of ADRs by its type of reaction.

\begin{tabular}{|lcc|}
\hline Type of ADR & \multicolumn{2}{c|}{ ADR } \\
\hline A & N & Percentage \\
\hline B & 39 & 73.58 \\
\hline Total & 14 & 26.42 \\
\hline
\end{tabular}

ADR: Adverse drug reaction

Table 4: Distribution of ADRs according to its severity.

\begin{tabular}{|lcc|}
\multicolumn{1}{c}{ Severity } & \multicolumn{2}{c|}{ ADR } \\
\hline Mild & 22 & Percentage \\
\hline Moderate & 28 & 41.51 \\
\hline Severe & 3 & 52.83 \\
\hline Total & 53 & 5.66 \\
\hline
\end{tabular}

ADR: Adverse drug reaction 
Table 6 shows that of 500 patients who received ACEI, 53 patients developed ADRs, hence, the rate of incidence was $10.60 \%$. Among them, 24 (4.80\%) patients developed dry cough, $8(1.60 \%)$ patients developed hypotension, $2(0.40 \%)$ developed headache, $2(0.40 \%)$ developed dizziness, $3(0.60 \%)$ developed nausea/bowel upset, $3(0.60 \%)$ developed rashes, $2(0.40 \%)$ developed angioedema, $3(0.60 \%)$ developed dysgeusia, $1(0.20 \%)$ developed hyperkalemia, $1(0.20 \%)$ developed ARF, whereas $1(0.20 \%)$ developed proteinuria, and $3(0.60 \%)$ developed other side-effects.

\section{DISCUSSION}

In our study, the male population taking ACEIs are more prone to ADRs than females. According to a recent survey, overall tolerability of antihypertensive medicines is likely

Table 5: Distribution of ADRs according to WHO-UMC causality scale.

\begin{tabular}{|lcc|}
\hline \multirow{2}{*}{ Classification category } & \multicolumn{2}{c|}{ ADR } \\
\hline Certain & N & Percentage \\
\hline Probable/likely & 7 & 13.21 \\
\hline Possible & 30 & 56.60 \\
\hline Unlikely & 8 & 15.09 \\
\hline Conditional (unclassified) & 4 & 7.55 \\
\hline Un-assessable (unclassifiable) & 3 & 5.66 \\
\hline Total & 1 & 1.89 \\
\hline
\end{tabular}

ADR: Adverse drug reaction

Table 6: Distribution of ADRs with individual drugs.

\begin{tabular}{|llc|}
\hline ADRs/Number of ADRs & Drug & N \\
\hline Cough/24 & Enalapril & 12 \\
& Ramipril & 9 \\
& Lisinopril & 2 \\
& Perindopril & 1 \\
\hline Hypotension/8 & Enalapril & 5 \\
& Ramipril & 2 \\
& Lisinopril & 1 \\
\hline Headache/2 & Enalapril & 2 \\
\hline Dizziness/2 & Enalapril & 2 \\
\hline Nausea/bowel upset/3 & Enalapril & 2 \\
& Ramipril & 1 \\
\hline Rashes/3 & Enalapril & 3 \\
\hline Angioedema/2 & Enalapril & 2 \\
\hline Dysguesia/3 & Enalapril & 3 \\
\hline Hyperkalemia/1 & Enalapril & 1 \\
\hline ARF/1 & Enalapril & 1 \\
\hline Proteinuria/1 & Enalapril & 1 \\
\hline Others/3 & Enalapril & 2 \\
& Lisinopril & 1 \\
\hline Total & & 53 \\
\hline ADR:Adverse & & \\
\hline
\end{tabular}

ADR: Adverse drug reaction, ARF: Acute renal failure to be similar in men and women. ${ }^{3,8,9}$ Most of the ADRs were moderate or mild, only 3 ADRs (5.66\%) were severe, like angioedema and ARF.

In our results, we have noted that majority $(56.60 \%)$ of ADRs by ACEIs belong to probable/likely category of WHO-UMC causality assessment scale, followed by possible (15.09\%) and certain (13.25\%). While in other studies, most of the ADRs were belonged to possible (47.10\%), followed by probable and certain. ${ }^{10}$

Most (73.58\%) of the ADRs by ACEIs found in our study were Type-A reactions as underlying mechanisms of ADRs like cough, hypotension, ARF, hyperkalemia, etc., can be explained. Only $26.42 \%$ ADRs were Type-B reactions.

In our study, incidence of total ADRs by ACEIs is $10.60 \%$, while a study conducted in the Capital of India reports that $22.30 \%$ of patients experienced ADRs. ${ }^{11}$ This shows relatively low rate incidence of ADRs by ACEIs in compare overall rate of incidence of ADRs.

Cough was the most common ADR of ACEIs in our study with the incidence rate of $4.80 \%$. The cough usually is persistent, paroxysmal, and nonproductive. Other studies reported dry cough due to ACEIs with the incidence rate of $5-10 \% .{ }^{12-14}$ One study reported higher incidence $(10 \%)$ of Fosinopril in compare to other ACEIs ${ }^{15}$ but in our study, fosinopril was not given to any patient.

The incidence of hypotension with the use of ACEIs is reported in the range of $2-5 \% .^{13,15-17}$ In our study, the incidence of hypotension was $1.60 \%$.

Nausea and bowel upset with the use of ACEIs is around $1-5 \% .^{13,15,17,18}$ It is somewhat higher with lisinopril. ${ }^{13,17,18}$ In our study, only $0.60 \%$ patients takings ACEIs reported nausea and bowel upset, due to enalapril and ramipril only.

Incidence of rashes in the literature ${ }^{19}$ is $1-4 \%$, while in our study it is $0.40 \%$ only. Same way, incidence of headache and dizziness in the literature is $1-4 \%$, in our study, incidence of headache is $0.40 \%$, and dizziness is $0.60 \%$, so collectively it is $1.00 \%$.

Angioedema is extremely rare and life-threatening ADR of ACEIs. In the literature, the incidence of it is $0.06-0.5 \% .{ }^{19} \mathrm{In}$ our study, it is slightly higher $(0.40 \%)$ than the average. This may be because our institute where this study was carried out is a tertiary care hospital.

Dysgeusia or reversible loss or alteration in taste sensation. In our study, the incidence of it is $0.20 \%$ only. In the literature, it is $0.5-3 \%$, slightly higher in captopril. ${ }^{19}$

Hyperkalemia $(0.20 \%)$, ARF $(0.20 \%)$ and proteinuria $(0.60 \%)$ are extremely rare ADRs of ACEIs, warrant withdrawal. 


\section{CONCLUSIONS}

From results and discussion of this study, we conclude that incidence of ADRs by ACEIs is $10.60 \%$ with cough as the most common ADR, followed by hypotension. Only few ADRs due to ACEIs are severe in nature, otherwise most are mild to moderate. As enalapril is most frequently used ACEI, ADRs due to enalapril are more common. A comparative pharmacovigilance study between two groups of ACEIs namely, p-ACEIs and d-ACEIs should be carried out to know the differences in patterns of ADRs between them.

\section{ACKNOWLEDGMENTS}

We are thankful to Dean, Dr. H.H. Agravat Sir, for allowing us to carry out this research project in our hospital. We are thankful to Dr. Saket Thaker (Sr. Resident DM Clinical Pharmacology, KEM Medical College), Whole Department of Pharmacology and whole Department of Medicine, for their help to accomplish this study.

Funding: No funding sources

Conflict of interest: None declared

Ethical approval: The study was approved by the Institutional Ethics Committee

\section{REFERENCES}

1. WHO. The Importance of Pharmacovigilane, Safety Monitoring of Medical Products. Geneva: WHO; 2002.

2. Edwards IR, Aronson JK. Adverse drug reactions: definitions, diagnosis, and management. Lancet. 2000 7;356(9237):1255-9.

3. Jose J, Rao PG. Pattern of adverse drug reactions notified by spontaneous reporting in an Indian tertiary care teaching hospital. Pharmacol Res. 2006;54(3):226-33.

4. Cannon RO 3rd. Potential mechanisms for the effect of angiotensin-converting enzyme inhibitors on endothelial dysfunction: the role of nitric oxide. Am J Cardiol. 1998 19;82(10):8S-10.

5. National High Blood Pressure Education Program Working Group report on hypertension in diabetes. Hypertension. 1994;23(2):145-58.

6. Central Drugs Standard Control Organization. Suspected adverse drug reaction reporting form. Available at http:// www.cdsco.nic.in/ADR_form_pvpi.pdf. Accessed 5 November 2011.

7. The use of the WHO-UMC system for standardised case causality assessment. Available at http//www.who-umc.org/ Graphics/24734.pdf. Accessed 5 November 2011.
8. Lewis CE, Grandits A, Flack J, McDonald R, Elmer PJ. Efficacy and tolerance of antihypertensive treatment in men and women with stage 1 diastolic hypertension. Results of the Treatment of Mild Hypertension Study. Arch Intern Med. 1996;156(4):377-85.

9. Montastruc JL, Lapeyre-Mestre M, Bagheri H, Fooladi A. Gender differences in adverse drug reactions: analysis of spontaneous reports to a Regional Pharmacovigilance Centre in France. Fundam Clin Pharmacol. 2002;16(5):343-6.

10. Hussain A, Aqil M, Alam MS, Khan MR, Kapur P, Pillai KK. A pharmacovigilance study of antihypertensive medicines at a South Delhi hospital. Indian J Pharm Sci. 2009;71(3):338-41.

11. Parthasarathi G, Olsson S. Adverse drug reactions. In: Pharthasarathi G, Nyfort-Hansen K, Nahata MC, editors. A Textbook of Clinical Pharmacy Practice. 1st Edition. Chennai: Orient Longman Pvt. Ltd.; 2004: 84-102.

12. Amolt MA, Damonte de Elia AR. Enalapril and cough. J Hypertens. 1991;4:28A.

13. Moyses C, Higgins TJ. Safety of long-term use of lisinopril for congestive heart failure. Am J Cardiol. 1992;70(10):91C-7.

14. Williams B, Gosse P, Lowe L, Harper R, PRISMA I Study Group. The prospective, randomized investigation of the safety and efficacy of telmisartan versus ramipril using ambulatory blood pressure monitoring (PRISMA I). J Hypertens. 2006;24(1):193-200.

15. Bristol-Myers Squibb. Fosinopril prescribing information. Princeton (NJ); 1996.

16. Cooper WD, Sheldon D, Brown D, Kimber GR, Isitt VL, Currie WJ. Post-marketing surveillance of enalapril: experience in 11,710 hypertensive patients in general practice. J R Coll Gen Pract. 1987;37(301):346-9.

17. Chu CS, Cheng KH, Lee KT, Lin TH, Lee ST, Su HM, et al. Tolerability of ramipril $10 \mathrm{mg}$ daily in high-risk cardiovascular patients in Taiwan: experience from Kaohsiung Medical University Chung-Ho Memorial Hospital. Kaohsiung J Med Sci. 2005;21(11):511-6.

18. Schreiner M, Berendes B, Verho M, Langley A, Cairns V. Antihypertensive efficacy, tolerance, and safety of longterm treatment with ramipril in patients with mild-tomoderate essential hypertension. J Cardiovasc Pharmacol. 1991;18 Suppl 2:S137-40.

19. Tripathi KD. Drugs affecting renin-angiotensin system and plasma kinins. Essentials of Medical Pharmacology. $6^{\text {th }}$ Edition. New Delhi: Jaypee Brothers; 2009: 479-92.

doi: $10.5455 / 2319-2003 . i j b c p 20141028$

Cite this article as: Trivedi MD, Kotadiya FS,

Bavaliya MK, Tilva BV, Mehta DS. Pharmacovigilance study of angiotensin-converting enzyme inhibitors in patients visiting Department of Medicine of a Tertiary Care Hospital, Surendranagar, Gujarat. Int J Basic Clin Pharmacol 2014;3:870-3. 